\title{
Recent Advances in Studies on Avian Malaria Parasites
}

\author{
Alfonso Marzal \\ University of Extremadura \\ Spain
}

\section{Introduction}

In 1902, Sir Ronald Ross was awarded the Nobel Prize in Medicine for his discovery of the mosquito transmission of malaria. This finding was achieved working with avian malaria and its vector, giving him a control over his experimental subjects difficult to attain with human models. Since then, malaria parasites of birds have played an essential role as a model in human malaria studies. Important advances in medical parasitology such of the study of the life cycle, development of chemotherapy, and cultivation in vitro have initially been developed using bird haemosporidian models. Significant anti-malarial compounds such as plasmochin, primaquine and atebrin were evaluated in bird model. In the same way bird parasites were used for drug testing and for further malaria-associated experiments. Nowadays, research on bird malaria is at the very peak since scientists have realized the benefits of using studies on avian malaria to answer ecological, behavioural and evolutionary questions. This review will highlight the importance of studies on avian malaria, showing the results of some recent investigations on this topic and describing new applications of avian malaria researches that could be useful for conservation and health policies in 21th century.

\section{Studies on avian malaria parasites}

Haemosporidians (Sporozoa: Haemosporida) are one of the most well known groups of parasitic protists. They include the agents of malaria, one of the most lethal human diseases. But the systematic and ecological diversity of malaria parasites is much larger. Systematic parasitologists have erected more than 500 described species belonging to 15 genera within the order Haemosporidia (Phylum Apicomplexa) that infect squamate reptiles, turtles, birds, and mammals, and use at least seven families of dipteran vectors (Levine, 1988; Martinsen et al., 2008). These parasites are distributed in every terrestrial habitat on all the warm continents.

Bird haemosporidians are the largest group of haemosporidians by number of species. Avian malaria and related haemosporidians are widespread, abundant and diverse and are easily sampled without disrupting the host populations. In addition, experimental studies on bird malaria usually present bigger samples sizes than primate or human studies, achieving a high degree of precision and confidence in the outcome of the study. More than 
200 parasite species of the genera Plasmodium, Haemoproteus and Leucocytozoon have been morphologically described among the 4.000 bird species investigated worldwide (Valkiūnas, 2005). All these characteristics turn bird blood parasites into an excellent model for the study of host-parasite interactions.

The term "malaria parasites" has been a controversial issue among parasitologists, ecologists and evolutionary researchers (Pérez-Tris et al., 2005; Valkiūnas et al., 2005). The debate stems from the incomplete knowledge of the phylogenetic relationships and pathogenicity of non human malaria parasites. The life cycles of Plasmodium, Haemoproteus and Leucocytozoon are similar, but they differ in important aspects. Looking at these differences in vectors, life cycles and epidemiology of these organisms, the traditional view accepts only Plasmodium species as being the true malaria parasites (Valkiūnas et al., 2005). The presence of both erythrocytic schizonts and gametocytes in infections with Plasmodium is a key difference from Haemoproteus and Leucocytozoon (these two latter undergo schizogony only in fixed non-circulating cells in the host) which is important for the identification, pathogenicity and experimental transmission of Plasmodium. Species of Plasmodium can be transmitted from infected to uninfected hosts by simple blood inoculation, while Leucocytozoon and Haemoproteus need an arthropod vector. These vectors are different among the three genera: blood-sucking mosquitoes are the main vectors of avian Plasmodium, whereas biting midges and hippoboscid flies are the vectors of Haemoproteus and simuliid flies transmit Leucocytozoon. The number of merozoites produced in schizonts also differs among haemosporidians. Some species of Leucocytozoon and Haemoproteus form megalozhizonts in host tissues that yield millions of merozoites, species of Plasmodium form smaller tissue schizonts that produce tens to hundreds of merozoites (Atkinson \& van Riper, 1991).

However, based on recent molecular genetic studies describing the phylogeny of the group, other authors include other genera, particularly Haemoproteus, among the malaria parasites (Pérez-Tris et al., 2005). Since the introduction of polymerase chain reaction-based methods for parasite identification (Bensch et al., 2000), research in avian malaria has boosted. Also, the publication of genetic database of these parasites based on mitochondrial cytochrome $b$ lineages (Bensch et al., 2009) has provide a valuable tool for cooperation between research groups and benefit the understanding of the ecology, evolution and taxonomy. In consequence, the number of scientific publications on this topic has remarkably increased in last decade (Figure 1). In this chapter I summarize some of the most recent advances in the study of malaria of birds, stating the solutions that avian malaria offers to human malaria research.

\subsection{Importance of studies on avian malaria}

Only five years later than Charles Louis Alphonse Laveran discovered the human malaria, in 1885 the Russian physiologist and protistologist Vassily Danilewsky found intraerythrocytic parasites in the blood of amphibians, birds and reptiles. He described in great detail the morphology of the various forms he observed, becoming aware of the fact that parasites from birds resembled the malaria parasites described by Laveran, Marchiafava and Celli. Intrigued and highly motivated with such similarities, he developed many ecological, anatomical and pathological investigations on infected birds, showing that the haemosporidiosis was accompanied by anemia, enlargement and whitening of the 
spleen and liver, and an accumulation of pigment. He also noticed some seasonality in parasitemia, where the presence of blood parasites in birds was higher during warm seasons. In 1888, he published a monograph in Russian on bird Haemosporidia, identifying and describing the main characters of the three main genera. But it was not until his three volume book La Parasitologie Comparée du Sang had been published in French in 1889 that this information became widely available. This monograph drew Laveran's attention and he studied with interest Danielewsky's results. In 1891, Laveran urged physicians to enter the domain of naturalists and to research bird malaria (Sá, 2010, Valkiūnas, 2005). This example clearly illustrates that human and avian malaria researches are intimately linked.

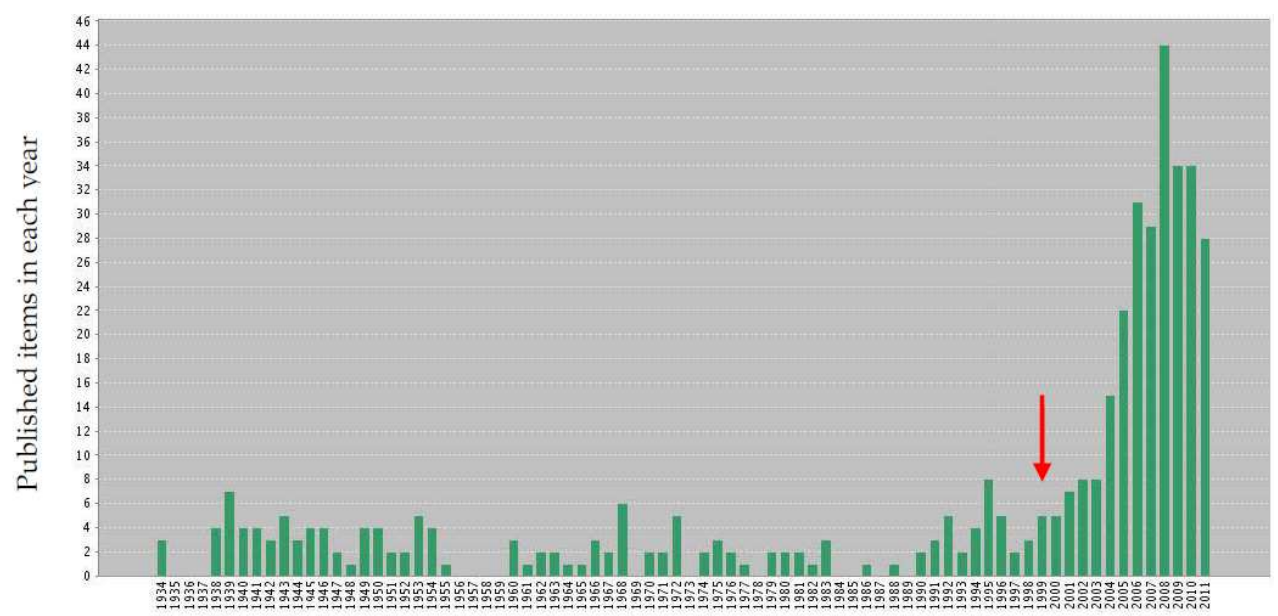

Fig. 1. Increase in number of articles published within the framework of "avian malaria" and "bird malaria" over the period 1934 - 2011. The figure is based on a literature search in the ISI-Web of Science (Thomson, September 2011). Arrow shows publication of Bensch et al. (2000).

As we have seen, from its origin research on bird malaria parasites has played an important role as human malaria research. Experiments with avian malaria contributed a great deal to our understanding of the life cycle of the human malaria parasite. In addition, the fundamental studies on chemotherapy of malaria were carried out with birds, and resulted in the discovery of two very well known synthetic drugs, plasmochin and atebrin. The most remarkable scientific advance linking avian and human malaria was done by Sir Ronald Ross (Figure 2), a British officer in the Indian Medical Service. Because malaria was a devastating health problem in India, he began to study its cause in 1890. For a long time malaria was thought to be spread by odours, and vapours produced in swamps were blamed as the origin of malaria infection. But Laveran verified the presence of pigmented bodies of parasites in the blood of malaria infected patients, suggesting an alternative cause. In that time, Ross believed that malaria was caused by an intestinal infection, following numerous failed attempts to infect human "volunteers" with water contaminated with malarial mosquitoes and larvae. In 1894, Sir Patrick Manson informed to Ross about Laveran's observation and suggested that mosquitoes, and not the water, were responsible 
for transmitting these parasites to humans. Ross began to breed mosquitoes for experimental research on malaria inoculation in humans. Finally, in 1897, he managed to get mosquitoes to feed on malarial patients and found evidences of the parasite within the stomach cavities of Anopheles mosquitoes. But during these researches on human models he found many frustrating obstacles, including a transfer within the Service prevented further work with human "volunteers", and his malaria research seemed to aim to an ending point. He still had, however, access to laboratory facilities. And he remembered that in 1894 Manson had suggested to him the idea of using malaria parasites of birds in his investigations. Ross then turned his attention to avian malaria parasites, giving him a control over his experiment subjects difficult to attain with human models. Working with caged birds, Ross confirmed the transmissive way of spreading of malaria, revealing the further development of the avian malaria parasite in the body of the mosquito. He followed the parasites Plasmodium relictum from an infected bird into the stomach of a Culex mosquito which had fed on the bird and from there to the mosquito's salivary glands. The bite of this mosquito then transmitted the malaria parasite to another bird. For this discover, Ross was awarded the Nobel Prize in 1902. At this point, it should be stressed that the first out of the four Nobel Prizes bestowed to malaria researches was awarded on investigations on avian malaria.

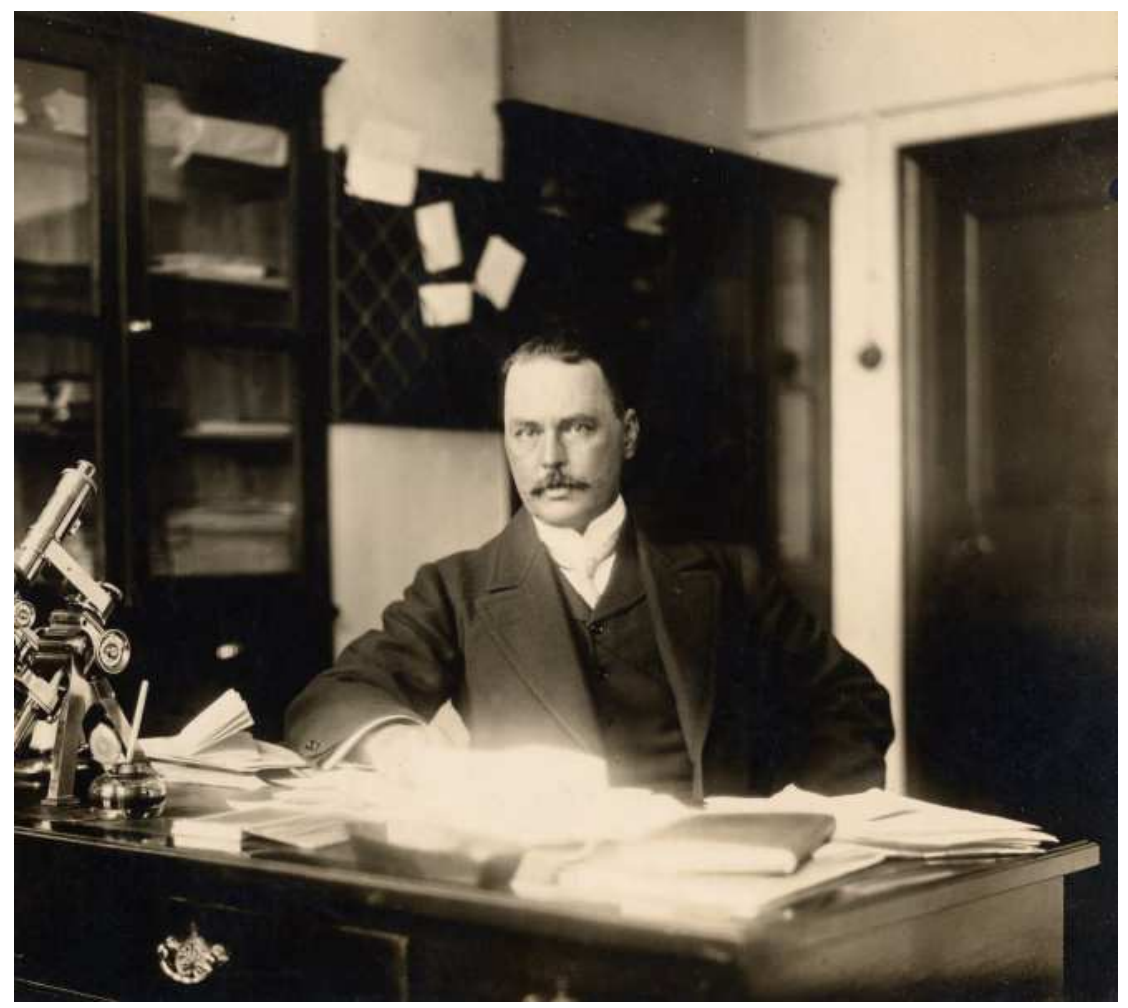

Fig. 2. Sir Ronald Ross (1857 - 1932), in 1904 at the Liverpool School of Tropical Medicine. 
Malaria has shaped the course of wars for millennia. In many conflicts, more troops were killed by malaria than in combat. In World War I, British, French and German armies were immobilized in Macedonia for 3 years by malaria. In this area, nearly 80 percent of French troops were hospitalized with malaria and 25.000 British soldiers were sent home with chronic malaria. German soldiers also suffered from the shortage of quinine, hampered his missions on East Africa, Balkans and Turkey. In this and other conflicts, avian malaria research has played a decisive role. In his book "War and disease", Slater (2009) highlighted the importance of avian investigations for biomedical research on malaria in the twentieth century. In 1910's German company Bayern invested many resources in the development of synthetic anti-malaria drugs. With this purpose, Wilhelm Roehl, a former assistant of Paul Ehrlich, joined the Bayer research group. Roehl believed that malaria research was hindered by the lack of good model system for research. He noticed that treatments against human malaria were also effective against avian malaria, but nobody had tested the reverse: to discover a new effective anti-malaria substance in birds that later proved effective on human malaria. And he did it. With his discover of synthetic compound plasmochin, Roehl was successful extending his finding from the bird to human malaria (Slater, 2009). Some years later, avian malaria research also played a major role in the World War II. During the first years of operations in the South West Pacific, the losses caused by malaria disease among the Allies greatly exceeded the number of battle casualties. In response to such situation, governments from United States and Britain started research and development programs to discover new anti-malarial drugs. Thousands of new anti-malarial drugs synthesized during the war, such as sulphadiazine group of drugs and amino-quinolines, were tested in first instance on malaria infected birds. And only those with high activity and low toxicity were then tested in humans (Fairley, 1947; Sweeney, 2000). It is clear that without this valuable information from bird malaria, the use of anti-malaria drugs by man would have been greatly curtailed.

Ross and Roehl's studies represent the peak achievement of discoveries in avian malaria research. However, the list of contributions of avian malaria investigations to human malaria research is striking. The formation of chemical therapy (Wasielewsky, 1904; Sergent and Sergent, 1921), the first cultivation methods of the tissue and erythrocytic stages in vitro (Ball \& Chao, 1961; Trager, 1947), and first steps in the development of antimalarial vaccines (McGhee et al., 1977) were first successfully achieved on the model of bird malaria parasites. Moreover, avian malaria was the most extensively model for tests of blood schizonticides, allowing the examination of new anti-malaria compounds in different birds, such as chicken, canaries, pigeon and ducks. With the implantation of the rodent malaria models, avian malaria research in Medicine fall into disuse. After the discovery of the rodent malaria parasite in 1950 and experimental inoculation of the three-striped night monkey with human malaria in 1966, the interest in research of medical parasitologists on bird haemosporidians decreased. At present, the low cost and easily availability of models of bird Plasmodium spp. have not lost their practical importance, primarily in immunological, genetic, biochemical and ecological investigations (Valkiūnas, 2005). Nowadays, there are increasing evidences that Plasmodium facilparum have become resistant to almost every antimalarial drug. Moreover, in some endemic areas of the world some P. facilparum isolates have developed multi-resistance to most available anti-malarial, especially to those in the aminoquinoline group (chloroquine, amodiaquine and mefloquine). Even recently it has 
been reported some causes of malaria resistance to the up to now effective combination of artemisinin derivatives with other antimalarials. Since History shows that once resistance emerges, it can swiftly travel around the world, these resistances constitute an enormous threat to the malaria control programs, making the development of new anti-malarial drugs urgent (Krettli et al., 2009). Once again, animal models for anti-malarial screening, like avian models, become important in the fight against human malaria. In recent times it has been suggested that avian malaria models would be especially important in places where there are no Anopheles mosquitoes raised indoors available to infect with mammalian malaria (Krettli, 2009). Also, they would be very useful in testing of new prophylactic compounds able to inhibit sporozoite development. For instance, a Brazilian medicinal plant species (Ampelozizyphus amazonicus) has successfully been examined demonstrating its prophylactic activity when tested in vivo against sporozoite-induced infections in an avian model (Krettli et al., 2001). In addition, the avian malaria P. gallinaceum is very useful in studying the activity of compounds (e.g. primaquine) aiming to cure the late relapse caused by $P$. vivax (Krettli et al., 2009).

By the other hand, the widespread geographic distribution of avian malaria parasites and their broad range of host species make them excellent models for exploring the ecological and evolutionary dynamics of host-parasite associations, including human malaria parasites (Fallon et al., 2005). Issues such as conservation of endemic fauna (Atkinson et al., 2000), speciation (Perez-Tris et al., 2007), co-evolution (Charleston and Perkins, 2002; Mu et al., 2005), life-history tradeoffs (Jovani, 2002), the evolution of virulence (Bell et al., 2006; Schall, 2002), sexual selection (Spencer et al., 2005), and competition and community structure (Fallon et al., 2004; Paul et al., 2002) have been studied in last ten years in avian malaria models.

In 21th century, Emerging Infectious Diseases are on the major threat to animal biodiversity and human health. Millions of organisms have experience, and likely will suffer the devastating effects of the rapid increase of these of new and existing infectious diseases. Recently it has been proposed that climate change could alter the equilibrium between parasites and host, potentially resulting in an epidemic. Wild bird populations are widely infected with Plasmodium and related haemosporidians, providing very precious information for the study of environmental threats such as climate change (Huijben et al., 2007). However, the factors favouring malaria outbreaks go beyond the basic biological elements and include ecological as well as socio-economic factors (Wilson, 2001). Since vectors populations and reproductive biology of malaria parasites are affected by climate change at a global scale, the resulting increase in malaria transmission should also be evident in birds. In human malaria studies it is very difficult to know if the change in parasite prevalence is due to socio-ecological factors or to the effect of climate change. But these confounding effects are irrelevant in the context of parasites that infect wild animals. Recently, Garamszegi (2010) compiled data on avian malaria and analyzed 43 surveys covering a time span from the 1940s to the present. Together, the surveys provided data on more than 3,000 bird species that had been screened for malaria in different regions. He found that avian malaria has nearly tripled in the last 70 years, in parallel with increasing global temperatures. And the most dramatic increases took place during the past 20 years. This avian study will be very valuable to improve our understanding of the effect of climate change on malaria in humans. 
Summarizing, research on bird malaria parasites has played an important role in human malaria research. The practical importance of bird haemosporidians should not be underestimated. For many years, they represent a stimulus for the development of medical parasitology. Notable advances in malaria research such as development of chemotherapies and vaccines, cultivation in vitro and study of life cycles, as well as other evolutionary, genetic and immunological investigations, have been possible thanks to avian models. Far from loosing validity, studies on avian malaria represent a formidable model for researchers, providing valuable tools to face new health and environmental challenges in 21th century.

\subsection{Pathogenicity of avian malaria parasites}

Malaria parasites are supposed to have strong negative effects on host fitness because this group of intra-cellular parasites causes dramatic reductions in the efficiency of metabolism (Chen et al., 2001). The infection begins with the bite of an insect inserting sporozoite stages from its saliva into the blood stream of the host. Then the development of extraerthrocytic meronts starts by asexual division inside internal organs for several generations (a minimum of two generations) until penetration into erythrocytes gives rise to gametocytes. This extraerythrocytic step is very important in order to improve the initial infectious source. Once intensity of infection has increased, a few merozoites penetrate into red blood cells to initiate the erythrocytic cycle producing macro- and microgametocytes by sexuall division (Valkiūnas, 2005; Wakelin, 1996). After a period of growth there is production of new erythrocytic meronts (schizonts). The infected cells then burst, releasing merozoites that will infect red blood cells, so that a high proportion of available erythrocytes may become infected. Erythrocytic cytoplasm and hemoglobin is digested by the parasite to obtain amino acids, but the haem is stored in the form of an insoluble pigment. When infected red blood cells burst, pigment and other metabolic products are released into the circulation, inducing the characteristic fever and other symptoms of illness (Wakelin, 1996). During the exoerythrocytic meronts stage there are pathological changes such as blocking of brain capillaries and capillaries of other vital organs thereby producing anoxia, death of cells and necrosis of tissues (i.e. liver and spleen). The most severe pathology happens in the blood stage, when destructions of host blood cells provoke acute anemia. Other consequences of malarial parasites infections include development of pneumonia-like symptoms and excessive enlargement of the spleen and liver that eventually causes rupture (Valkiūnas, 2005).

Previously blood parasites were considered low pathogenicity organisms (Weatherhead \& Bennett 1992; Bennett et al. 1993) in spite of them causing disease and death in captive birds. Other studies demonstrated subtle but important effects of hematozoan parasites on the life history of their avian hosts (Allander \& Bennett 1994; Dufva 1996; Korpimäki et al. 1993, 1995; Rätti et al. 1993). However, some researchers did not find detrimental effect of these parasites (Fallis \& Desser 1977; Dufva \& Allander 1995; Dawson \& Bortolloti 2000). Therefore, there are no clear conclusions about parasite pathogenicity and about regulation of their host populations. The main problem of most of these studies is the lack of experimentation. The demonstration of effects of parasites requires an empirical approach, where experimental manipulation of natural blood parasite loads may reveal their harmful effects (Keymer \& Read 1991; Knowles et al. 2010; Merino et al. 2000). In this sense, two have 
been the most successful methodologies employed for experimental approaches to test for fitness effects of avian malaria infection: i) direct inoculation of a parasite on uninfected individuals, and ii) experimental removal of parasites through medication.

The experimentally removal of parasites by anti-malaria medication has been a popular methodology to test the fitness consequences of avian malaria infection. Following this procedure, Merino et al. (2000) reduced through medication the intensity of infection by Haemoproteus majoris and the prevalence of infection by Leucocytozoon majoris in blue tits Cyanistes caeruleus. Medicated females then devoted more resources to parental care and, consequently, increased their reproductive success. This experimental reduction of parasite load revealed the causality in the association of natural infection levels with life-history variables.

But clutch size, one of the most important reproductive patterns in birds, could also be affected by malarial parasites. In addition, if malarial parasites have early effects on the reproductive cycle then they could have disproportionately large effects on seasonal reproductive success. In this line, Marzal et al. (2005) studied the effect of Haemoproteus spp. on the reproductive success of migratory house martin Delichon urbica. At the beginning of the breeding season they experimentally reduced levels and intensity of Haemoproteus infection, by randomly treating birds with an anti-malarial drug (primaquine). The results showed that clutch size was on average $18 \%$ larger in treated birds, while these differences increasing to $39 \%$ at hatching and $42 \%$ at fledging. These findings demonstrated that malarial parasites can have dramatic effects on clutch size and other demographic variables, potentially influencing the evolution of clutch size, but also the population dynamics of heavily infected populations of birds.

In the same year, Tomás et al. (2005) studied the role of blood parasites as a potential source of physiological stress for avian hosts in the wild. Through a medication, they reduced the intensity of infection by Haemoproteus majoris and the prevalence of infection by Leucocytozoon majoris in female blue tits Cyanistes caeruleus. They showed an increase in stress proteins (heat shock proteins) in control females in compare to medicated ones, reporting the first experimental evidence relating blood parasite infection to the physiological stress response in a wild avian population.

Because intensity of blood parasite infection varies during infection, the dynamics of infection could have been the cause of difficulties for detecting their fitness effects in wild populations of birds. During the brief acute stage of a haemosporidian infection, parasites usually appear in the blood at high density and hosts can suffer marked mortality (Atkinson \& van Riper, 1991; Valkiūnas, 2005). However, in individuals that survive the acute stage, long-term chronic infections develop, in which parasites persist at low density and are thought to be controlled by acquired immunity (Atkinson \& van Riper, 1991). Recently, two studies have shown the negative effects of this malaria chronic infection to their avian hosts. Martínez de la Puente et al. (2010) have experimentally demonstrated long-term direct survival costs of chronic Haemoproteus infection in wild birds. They medicated males and females blue tits Cyanistes caeruleus with primaquine. This anti-malaria drug reduced the intensity of Haemoproteus infection in females, but not in males, showing a sex-specific effect of medication on Haemoproteus intensity, probably due to sex effects on drug kinetics. Medicated females, but not males, showed increased local surviving until the next breeding 
season compared to control birds. In addition, Knowles et al. (2010) have illustrated that chronic avian malaria infections can have significant effects on host fitness and may thus constitute an important selection pressure in wild bird populations. They used the antimalarial drug Malarone ${ }^{\mathrm{TM}}$ to test experimentally for fitness effects of chronic malaria infection in blue tits Cyanistes caeruleus. The recently developed molecular methodology quantitative PCR revealed that medication caused a reduction in Plasmodium infection intensity, leading to a higher hatching success, provisioning rates and fledging success.

On the other hand, experimental inoculation of avian malaria parasites from infected donors has also been widely used by researchers to study the harmful effects of parasitic infection. Atkinson et al. (1988) were among the first researches experimentally demonstrating the detrimental effects of Haemoproteus infection in birds. With a sporozoite-induced experimental infection of Haemoproteus meleagridis, they showed the pathological effects of such infection in domestic turkeys. Some years later, Garvin et al. (2003) studied the pathogenicity of Haemoproteus danilewsky in captive blue jays Cyanocitta cristata. By mean of an intraperitoneally inoculation of $3.000-4.000$ sporozoites of $H$. danilewsky obtained from Culicoides edeni (Diptera: Ceratopogonidae), they showed sublethal pathologic changes in the liver, lung and spleen of birds. Also, Valkiūnas et al. (2006a) infected nestling blackcaps Sylvia atricapilla by inoculation in their pectoral muscle with 45 sporozoites of Haemoproteus belopolskyi developed in the experimentally infected biting midge Culicoides impunctatus. When compared with controls, they showed that experimentally infected birds suffered from a significant weight loss, indicating a short-term influence of the infection on the birds' body mass. Some years later Palinauskas et al. $(2008,2009)$ carried out some experimental inoculations on captive passerines to test for the susceptibility of different hosts to the same malaria parasite. They evaluated the effects of Plasmodium relictum (lineage P-SGS1), which is a host generalist, to five species of passerine birds. They demonstrated that the same parasite lineage can cause malaria of different severity even in phylogenetically closed related bird species.

Studies based on microscopic examination of thin blood smears have revealed that parasitized birds may frequently carry several different parasites (Palinauskas et al., 2005; Valkiūnas, 2005). In addition, recent advances in methods of genotyping have shown that the number of avian malaria species is much higher than can be distinguished by traditional methods (Bensch et al., 2004), revealing coinfections by different parasite lineages or genera (Hellgren, 2005; Pérez-Tris \& Bensch, 2005). For example, a recent study combining molecular and traditional methods found this mixed infections in more than 43 percent of the examined birds (Valkiūnas et al., 2006b). But besides this abundance, the effects of simultaneous infections of avian malaria parasites are largely unknown.

Although antagonistic effects between parasites have been described in some studies (Fenwick, 1980; Juhl \& Permins, 2002), some others have found synergetic effects between two malaria parasites infecting simultaneously (Taylor et al., 1998; Zehtindjiev et al., 2008). In this sense, theory predicts that multiple infections could be especially injurious for hosts, leading to anaemia, loss of body mass and reduced survival (Graham et al., 2005; Davidar \& Morton, 2006). Such effects of malaria double infections have been poorly investigated and the reported results are inconclusive. For instance, Sanz et al. (2001) found no relationship between primary reproductive parameters and the number of blood parasite species infecting female pied flycatchers Ficedula hypoleuca. On the other hand, Evans \& Otter (1998) 
showed a lethal combined effect of infections with Haemoproteus and Leucocytozoon in juvenile snowy owls Nyctea scandiaca, although both parasite species on their own were not considered to be pathogenic. In 2008, Marzal et al. investigated the effects of single and double malaria infections on survival, body condition and reproductive success in house martins, using the performance of uninfected individuals as a reference. They expected to observe a trend in pathogenic consequences from uninfected to single-infected to doubleinfected birds. Their finding showed that the infection with malaria parasites had detrimental effects on house martins, as shown by the decreased survival prospects of double- and single-infected individuals. The negative effects of infection were detectable in reduced body condition of double-infected house martins, but not in single-infected ones. But surprisingly and contrary to their predictions, individuals harboring a double infection invested more in current reproduction, despite being in poor physical condition. More recently, Palinauskas et al. (2011) have shown that co-infections of Plasmodium relictum and Plasmodium ashfordi are highly virulent and act synergistically during primary infections in some but not all passerine birds (Palinauskas et al., 2011).

At the same time, however, in many of these above studies is quite frequent to find infected individuals that seem do not suffer from detrimental effect of blood parasites (e.g. no negative effect on survival and/or reproductive success). The question arising from here is why not all infected birds experience the pathological effect of malaria. Of course these differences could be explained by a sampling bias in these studies. In this sense, only relatively healthy specimens (uninfected birds or with low intensity of infection) are active and can be caught in mist nets or stationary traps, whereas bird weak due to heavy parasitemias are undersampled because they are inactive (Valkiūnas, 2005). Nowadays ecologists and evolutionary biologists are investigating how host organisms do defend themselves against parasites, dividing host defenses into two conceptually different components: resistance and tolerance. Following this line, once infected, hosts can resist the assault by minimizing the success of enemy harass directly attacking parasites and thereby reducing parasite loads. Or alternatively, they can tolerate the parasite limiting the injury caused by a given parasite burden and minimizing the fitness impact of enemy attacks (Råberg et al., 2009; Svensson \& Råberg, 2010). Recent evidence indicates that some native Hawaiian birds have developed some tolerance to malaria (Freed et al. 2005). This could lead to an increase of reservoirs of the disease, which in turn increases the risk of transmission to rarer species that are vulnerable to avian malaria. Whatever it is, it seems that pathogen burden and health are not always well correlated. Further experimental studies with the aim of quantifying both tolerance and resistance are needed for a better understanding of these co-evolutionary dynamics in host-parasite interactions.

To recapitulate, traditional studies on pathogenicity of avian malaria on wild populations of birds initially showed the negative consequences of the infection of this group of haemosporidian parasites. These and new detrimental effects were later confirmed by empirical studies, either by means of experimental inoculation of the parasites on uninfected birds or by removal of infection after an anti-malarial medication. Nowadays, new advances in molecular methodologies combined with traditional microscopy will throw light for understanding the way in which parasites impose selection on hosts. 


\subsection{Malaria parasites as geographical markers in migratory birds}

Migratory birds have suffered a worldwide dramatic decrease in numbers in the past several decades (Terborgh, 1989). In 2010, BirdLife International found that population of $45 \%$ of Europe's common birds and more than $80 \%$ of Australia's wading species have declined. The exact reason for the birds' decline is a mystery, but scientists have begun to point out the possible basis for such downward trend. Several reasons have emerged as the greatest threats to their survival, mainly associated to disruption, fragmentation and destruction of breeding habitats, stopover sites and wintering grounds. This data are warning to us that environmental degradation is having a huge impact on all biodiversity, not only in birds. This deterioration of the environment contributes to health threats worldwide. Environmental degradation can have a significant impact on human health, ranging from death caused by cancer due to air pollution to psychological problems resulting from noise. Thus, a better understanding of the causes of the destruction of natural habitats and ecosystems can help to inform environmental policy design.

Migratory bird species can provide us with this information. They are excellent indicators of large-scale ecosystem health and landscape integrity. Moreover, because of the large distances they travel and sensitivity to minor ecological changes at sites across their established routes, migratory species are most likely to be affected by climate change and offer a hint into how ecosystems are changing. Since migratory individuals spend different periods of their annual cycle in widely separated and ecologically disparate locations, only the knowledge of the migratory connectivity could help us to identify the specific threats on the wintering location, stopover sites and breeding grounds of endangered migratory bird populations. Unfortunately, our current understanding of the migration routes and wintering areas of many migratory bird species is still limited. To solve this problem, researchers have employed several methods to determine migratory patterns and know the wintering areas with varying success. In recent times it has been suggested that parasites, specifically avian malaria and related haemosporidians, can be used as geographical markers in migratory birds. In this section I evaluate the studies that have been developed in the last ten years in this field, exploring several lines of research that might be worth following in the future.

In the beginning, researchers attempted to band birds by attaching a small, individually numbered, metal or plastic tag to their legs or wings in their breeding grounds and then recapture them on the wintering quarters. This technique has been used since 1899, and it has provided the most information about migration routes, stopover sites and wintering grounds for birds. Unfortunately, most ringed animals are never seen again and the number of rings recovered from sub-Saharan Africa is very low (Sillet \& Holmes, 2002). Alternatively, morphological variations can be used to directly track migratory birds, but the validity of this technique is limited to species with geographically segregated morphotypes (Webster et al., 2002). In recent years, satellite telemetry has been the most important advance in the field, allowing for a scale-independent tracking of individuals birds anywhere in the world. However, the current size and weight of even smaller satellite tags is too large (> $18 \mathrm{~g}$ ) to allow its use in small birds, which represent the vast majority of migratory birds (Webster et al., 2002).

While all these traditional capture-recapture and new techniques have been relatively inefficient for linking wintering and breeding habitats, other new advances in molecular 
ecology and stable isotope composition of animal tissues have provided promising results. Given that isotopic ratio in the local environments are incorporated into plants during nutrient uptake and then passed through local food chains, the isotopic composition of animal tissues reflects that of the local environment where those tissues were grown (Hobson et al., 2001). Then, isotopic markers have a great potential for identifying the source area where, for example, a migratory bird has moulted their feather during winter. However, some limitations should be considered such as variation in isotopic signatures with diet, altitude and trophic levels (Hobson et al., 2004; Hobson 2005; Wassenaar \& Hobson, 2000).

In 2002, Webster et al. proposed several genetic approaches to determine the geographical origins of bird sampled at particular sites. This technique is useful when genetic markers are specific to particular populations or subsets of populations. Unfortunately, birds are usually widespread dispersal and none or very weak genetic differentiation among population can be found when analyzing bird DNA. However, they also suggested an exciting and powerful genetic approach to measuring connectivity: to use the genes from organisms that birds carry (e.g. parasites) rather than genes from the birds themselves. Following this line, avian malaria parasites can provide valuable information about wintering or breeding sites since these vector-borne parasites can be transmitted only in the area where they coexist with the host. Moreover, new advances in amplifying and sequencing DNA from avian malaria has allowed the identification of different parasite lineages, providing information about parasite-transmission area at a finer scale.

The first approach to the use of avian malaria as geographical markers was even before than Webster's proposal. By microscopy scanning of blood smears, Rintamäki et al. (1998) showed differences in time of main occurrence of Haemoproteus and Leucocytozoon infection of migrating willow warblers Phylloscopus trochilus at a stopover sites. They suggested that these differences could indicate that the birds had become infected in different areas. Some years later, Waldenström et al. (2002) used molecular techniques to study the phylogeny of avian haemosporidian parasites in a number of African resident and European migratory songbird species. They showed three clades of avian malaria which transmission seems to occur solely in Africa, and two Haemoproteus clades that appeared to be transmitted both in wintering and breeding grounds.

After these promising results, Fallon et al. (2006) were not successful in the use of malaria parasites as geographical markers in migratory birds. They tested the hypothesis that malaria parasites could provide sufficient geographical signal to track population movements of black-throated blue warblers Dendroica caerulescens between breeding and wintering habitats in North America. They screened and genetically typed malaria parasites from more than 1.000 individual, showing that parasite lineages were geographically widespread and did not provide site-specific information.

More recently, Pagenkopp et al. (2008) analysed liver tissue and blood trying to determine whether haemosporidian parasite lineages detected significant geographic structure in common yellowthroats Geothlypis trichas. They compared Plasmodium lineages infecting birds showing some geographical structure, where some lineages seems to be more geographically specific than others, allowing some discrimination of origin. However, they concluded stating that this variation was not enough for their use as a marker of migratory connectivity. 
Yohannes et al. (2008) combined the study of the composition of stable isotopes in winter moulted feathers and the analyses of malaria parasites to track whether great reed warblers Acrocephalus arundinaceus wintering in different areas showed differences in blood parasite infection. They found marked differences in isotopic signatures when comparing infected and non-infected birds, showing that birds infected with malaria have moulted in different geographical areas than the non-infected birds. But they found no significant relationship between feather isotope value and malaria type, indicating that parasite composition was not related to moulting area.

By analysing the spatial and temporal differences in the blood parasite fauna of three species of warblers during the spring migration in Bulgaria, Shurulinkov and Ilieva (2009) illustrated spatial differences in the prevalence and composition of blood parasite fauna in two species. They argued that these differences found between sites could be explained with the different origin of the migrants at different migration stopover sites.

Finally, von Rönn has recently shown (2010) an association between stables isotopes composition in feathers moulted in the African winter quarters and the diversity and prevalence of malaria parasites in barn swallows Hirundo rustica. Hence, individuals wintering in different areas become infected with different Plasmodium parasites.

Summarizing, understanding the factors operating on environmental degradation could help us to identify the specific threats and predict ecological responses to changes in habitat quantity and quality. Since they spend different periods of their annual cycle in disparate locations, migratory birds are excellent bioindicators to estimate the environmental quality of diverse areas. In recent years, avian malaria parasites have been used to provide an excellent tool to track bird populations during migration, but the outcomes from these studies are not enough to complete our knowledge on migratory routes. Future researches with more migratory bird species combining multiple markers will provide vital information to preventing the decline and extinction of many organisms.

\subsection{Malaria parasites and avian invasion}

The total cost of Global nature destruction is estimated \$4,500 billion annually (The Economics of Ecosystems and Biodiversity [TEEB], 2010). Most of this biodiversity loss is provoked by intentional and unintentional introductions of non-indigenous species becoming invaders in new ecosystems. These invasive species are a greater threat to native biodiversity than pollution, harvest, and diseases combined. Also, invasive species can have substantial impacts on ecological systems, gene pools, and the disease environments for livestock, crops, and humans (Allendorf \& Lundquist, 2003; Mack et al., 2000; Mooney \& Cleland, 2001). Hence, understanding the causes of invasion success can help us to predict effects of species introductions and to design interventions.

Despite the economic importance of invasive species and the efforts from government organizations as well as conservation groups to understand biological invasions, the mechanisms that allow one species to become invasive are still poorly understood. Since many introduced species fail to establish or to spread significantly, but many others become successful colonizers, we questionnaire what makes a species a successful invader. Scientists have proposed several mechanisms to explain invasive, including species-based mechanisms (i.e. competition) and ecosystem-based mechanisms (i.e. availability of 
resources). Parasites and other pathogens have been proposed to play an important role on the invasive process, facilitating colonization and spread of their hosts in new continents and islands. Based on the analysis of traits of invasive species, two main hypotheses have been proposed to explain the mechanisms conferring invasiveness to the organisms. According to the Enemy Release Hypothesis, non-native species become successfully established because they are freed from their co-evolved pathogens, parasites and predators (Torchin et al., 2002; Colautti et al., 2004). Because parasites can reduce host population abundance, density and spread (Anderson \& May, 1978), this decrease in parasite pressure may allow introduced species to decrease their investment in defenses and maximize their capital in growth and reproduction, thus increasing their competitive ability and displace native species (Bloosey and Nötzold, 1995). Alternatively, the Novel Weapon Hypotheses proposes that introduced species possess allelopathic chemicals, parasites, and pathogens against which the introduced species but not the natives have evolved defenses (Callaway \& Ridenour, 2004; Prenter et al., 2004). Consequently, individuals and populations in their native areas can be seriously damaged by the pathogens brought with invaders.

Novel weapons have played a role in many human invasions. In his war against Incas, apart from steel armaments and horses, Pizarro relied on another powerful weapon: germs. Smallpox, brought to the Americas by the Spanish, had spread south from Panama well ahead of Pizarro's troops, becoming an epidemic with devastating consequence for the native people. As well as other endemic European diseases such as measles, influenza, typhus and bubonic plague, smallpox played a decisive role in European conquests. These novel weapons spread quickly in America, from tribe to tribe, killing an estimated $95 \%$ of the indigenous population far in advance of the European themselves (Diamond, 1997).

In last centuries, several bird species have been successfully introduced and become invaders in many parts of the world (Blackburn et al., 2009). Despite the large amount of information on the distribution, ecology, and evolution of birds could provide excellent opportunities for examining the factors that facilitate invasions, their biological invasions have received relatively little attention in compare to other organisms. Just recently some researchers have focused on avian species addressing important questions about the factors that facilitate invasions. In this line, malaria and related haemosporidian parasites have been proposed to play a major role on the successful colonization of exotic bird species. Next I present two of the most dramatic examples of the fatal consequences of introduction of birds, and a review of the latest scientific contributions explaining the importance of malaria parasites in avian invasions.

The Hawaiian Islands are some of the most isolated landmasses in the world, with approximately 70 million years of isolation for avian population (Mac et al., 1998). This isolation allowed the evolution of its species into endemism. Nowadays, many exotic bird species invaded Hawaiian forests displacing local species. This invasion seems to be prompted by a powerful allied: avian malaria. The introduction of avian malaria (Plasmodium relictum) and its active vector Culex quinquefasciatus in the Hawaiian Island of Maui in 1826 provided an excellent model system for studying the effect of exotic disease on naïve host populations. As an outcome of this fatal introduction, the mortality of resident birds increased up to $90 \%$ and many native species were extinct (Jarvi et al., 2001; Van Riper et al., 1986). This enormous mortality can be result of the long isolation period, where the Hawaiian bird populations did not have a close evolutionary history with avian malaria 
parasites. As a consequence of this lack of co-evolution, the relatively benign malaria parasites in the introduced exotic birds were highly virulent when infecting the naïve Hawaiian birds (Atkinson et al., 1995). Those exotic birds not only provided the original pathway for the introduction of avian malaria into the islands, but now they continue to contribute to its impact. Most of this foreign birds are malaria-resistant and do not suffer from its detrimental effects. However, they maintain low-level infections and act as reservoirs for this disease. Therefore, mosquitoes can feed on these low-infected birds and pass this novel pathogen on the naïve native species. As a consequence of this parasite pressure, many native birds can no longer breed in their historical breeding forests at lower elevations and are forced to breed in higher elevations grounds, which are free from mosquitoes but where food and cover may be scarce. By the other hand, in avian malaria studies, as well as in other organisms, the highest mortalities rates among the hosts are usually found to be associated to mixed infection with two or more malaria species (Marzal et al., 2008; Tang et al., 2010). However, this seems not to be the case in mortality induced by malaria in native Hawaiian birds. Despite thousands of shorebirds and ducks migrating to Hawaii and exotic bird released in last two centuries can have harbored hundreds of novel parasites, only the parasite lineage GRW4 from P. relictum seems to be the cause of the high mortality of many species of Hawaiian passerines (Beadell et al., 2007), showing the dramatic effects that a single novel malaria parasites can provoke in naïve hosts.

A similar situation reported in Hawaii is currently studied in New Zealand (Tompkins \& Poulin, 2006). In the earliest years of 20th century it was first postulated the connection between the extinction of New Zealand native birds and imported fauna through the exotic protozoa carried by these foreign birds (Doré, 1918). Exotic birds could act as reservoirs for these parasites and exacerbated disease problems for native avifauna. In addition, four different exotic species of mosquitoes were successfully established in New Zealand from 19th century, being Culex quinquefasciatus, the primary vector of avian malaria in Hawaii, among them (Laird, 1995). The increasing distribution of this vector could enhance the incidence of avian malaria, probably boosting the parasitemia in infected species, increasing its host range in areas where Plasmodium is already present, and/or increasing its geographical range in New Zealand (Tompkins \& Poulin, 2006). It seems plausible that malaria parasites could tip the scale in alien bird species favor when competing with local birds. And the situation is not promising: the impact of blood parasites on New Zealand birds and the colonization of exotic avifauna are likely to increase in the near future.

New Zealand and Hawaii Islands represent two of the most well known examples of Novel Weapon Hypothesis, where parasitism and species invasions interact to influence natural communities. But the opposite scenario is also possible in invasions of exotic birds. The Enemy Release Hypothesis is recently summoned as an explanation of the success of introduced bird species when arriving in a non-native region (MacLeod et al., 2005; Shwartz et al., 2009). It suggests that flourishing colonizers are successful because they have left behind their natural coevolved predators or pathogens. In consequence, successful colonizers do not have to invest in anti-parasite or anti-predators defenses and can reallocate resources into other important biological functions (e.g. reproduction and growth). In this sense, Shwartz et al. (2009) have shown that the release from predators facilitated the reproductive success and therefore the invasiveness of parakeets (Psittacula krameri) in new regions. 
Because of their deleterious effects on their host populations described above, removing weak individuals from wild populations (Valkiūnas 2005) or reducing hosts 'reproductive output (Marzal et al. 2005; Merino et al. 2000), avian blood parasites have been considered an interesting model to test the Enemy Release Hypothesis. Ishtiaq et al. (2006) were the first to study the avian blood parasites as a model to test this evolutionary hypothesis. They assessed the prevalence and distribution of malaria parasite lineages in the common myna Acridotheres tristis, a common passerine native to southern Asia that has been introduced to many parts of the world. Their results showed that not all comparisons of introduced populations to the native populations were consistent with the predicted Enemy Release Hypothesis. Moreover, they found some evidences of Novel Weapon Hypothesis, where common mynas carried parasite lineages from native to introduced locations. These mixed results could partially be due to the difficulty to differentiate between parasites that are native and introduced, because Haemoproteus and Plasmodium lineages infecting common mynas often did not show regional or host specificity.

Lima et al. (2010) also tested two predictions of the Enemy Release Hypothesis by comparing the presence and intensity of avian malaria parasites among house sparrows (Passer domesticus) and native birds from Brazil, as well as comparison with European house sparrows. Their results supported the hypothesis. According to their predictions, they found that native birds from Brazil presented significantly higher parasite prevalence. Also, they found that house sparrows native to Europe exhibited higher parasite prevalence than introduced house sparrows from Brazil, suggesting that sparrows from Brazil might have experienced a parasitic release during the process of introduction.

Just recently, an international team formed by 27 researchers has presented the most extensive study of the geographic distribution of a species rich group of parasites in a globally distributed vertebrate in the wild (Marzal et al., 2011). They examined these two important hypotheses (Enemy Release Hypothesis and Novel Weapon Hypothesis) to assess the role of avian malaria in the global spread of a common invasive bird. By analyzing prevalence and genetic diversity of malaria parasites in 58 localities on 6 continents, they showed that house sparrows did not retain their native parasites in newly colonized regions. In addition, house sparrows in non-native regions were exposed to a lower diversity and prevalence of haemosporidian infections than in their native range. They conclude that, since the house sparrows lost their native parasite when colonizing new regions, the release from these natural enemies may have facilitated its global invasion in the last two centuries.

To conclude, two points should be highlighted. First one, anthropogenic factors are almost always involved in biological invasions. Human introduction of animals to new geographical regions is usually accompanied by detrimental effects on native communities. Important and severe policies such as strict border control biosecurity regimes and controlled human traffic to remote populations or endangered species are necessary to prevent accidental or deliberate introductions. And second one, our current knowledge relevant to the disease effects of biological invasions is still poor. The allocation of resources in the research of biological invasions is essential to address this gap and design interventions, but mostly policies goes in the wrong way: current annual environmental, economic, and health-related costs of invasive species exceed the resources invested in the research of preventing biological invasions. 


\section{Conclusion}

Investigations of avian malaria have contributed significantly to the knowledge on biology and ecology of malaria parasites of other vertebrates, including human malaria. For almost 100 years, bird malaria parasites have been widely used as an experimental model in many laboratories for discovering and testing of new chemotherapies, development of antimalarial vaccines and cultivation in vitro of tissues and erythrocytic stages, helping save millions of human lives. In addition, the widespread geographic distribution of avian malaria parasites and their broad range of host species made them excellent models for exploring the ecological and evolutionary dynamics of host-parasite associations. Nowadays, far from being outdated, research on avian malaria is essential to fence new health and environmental challenges in this time of unprecedented global change. Climate change, the introduction of invasive species, urbanization, deforestation of natural environments and the loss of biodiversity are all implicated in increasing the spread of infectious pathogens such as malaria. Current and new advances in avian malaria research will be crucial to help predict and prevent outbreaks that could affect avifauna, humans and other wildlife worldwide in 21th century.

\section{Acknowledgment}

The author thanks INTECH for the invitation to write this review. The author also is grateful to Laszlo Z. Garamszegi and F. de Lope for helpful suggestions regarding the manuscript. Spanish Ministry of Education and Science (CGL2009-08976) and Junta of Extremadura (PRI08A116 and GRU10143) provided funding for this research.

\section{References}

Allander, K. \& Bennett, G. F. (1994). Prevalence and intensity of hematozoan infections in a population of great tits Parus major from Gotland, Sweden. Journal of Avian Biology, Vol. 25, pp. 69-74

Allendorf, F. W. \& Lundquist, L. L. (2003). Introduction: population biology, evolution, and control of invasive species. Conservation Biology, Vol. 17, pp. 24-30

Anderson, R. M. \& May, R. M. (1978). Regulation and stability of host-parasite population interactions: I. Regulatory processes. Journal of Animal Ecology, Vol. 47, pp. 219-247

Atkinson, C.T.; Forrester, D. J. \& Greiner, E. C. (1988). Pathogenicity of Haemoproteus meleagridis (Haemosporina: Haemoproteidae) in experimentallyinfected domestic turkeys. Journal of Parasitology, Vol. 74, pp. 228-239

Atkinson, C. T. \& Van Riper III, C. (1991). Pathogenicity and epizootiology of avian haematozoa: Plasmodium, Leucocytozoon and Haemoproteus. In Bird-Parasite interacctions, J. E. Loye \& M. Zuk (Eds.), 19-48, Oxford University Press, ISBN 9780198577386, Oxford, UK

Atkinson, C. T.; Woods K. L.; Dusek, R. J.; Sileo, L. S. \& Iko, W. M. (1995).Wildlife disease and conservation in Hawaii: Pathogenicity of avian malaria (Plasmodium relictum) in experimentally infected Iiwi (Vestiaria coccinea). Parasitology, Vol. 111, pp. S59-S69

Atkinson, C.T.; Dusek, R.J.; Woods, K.L. \& Iko, W.M. (2000). Pathogenicity of avian malaria in experimentally-infected Hawaii Amakihi. Journal of Wildlife Diseases, Vol. 36, pp. 197-204 
Ball, G. H. \& Chao, J. (1961). Infectivity to canaries of sporozoites of Plasmodium relictum developing in vitro. The Journal of Parasitology, Vol. 47, pp. 787-790

Beadell, J. S.; Ishtiaq, F.; Covas, R.; Melo, M.; Warren, B. H.; Atkinson, C. T., Bensch, S., Graves, B. R., Jhala, J. V., Peirce, M. A.; Rahmani, A. R.; Fonseca, D. M. \& Fleischer, R. C. (2006). Global phylogeographic limits of Hawaii's avian malaria. Proceedings of the Royal Society of London B, Vol. 273, pp. 2935-2944

Bell, A.S.; de Roode, J.C.; Sim, D. \& Read, A.F. (2006). Within-host competition in genetically diverse malaria infections: parasite virulence and competitive success. Evolution, Vol. 60, pp. 1358-1371

Bennett, G. F., Peirce, M. A.\& Ashford, R. W. (1993). Avian Haematozoa, mortality and pathogenicity. Journal of Natural History London, Vol. 26, pp. 993-1001

Bensch, S.; Stjernman, M.; Hasselquist, D.; Östman, O.; Hansson, B.; Westerdahl; H. \& Pinheiro, R. T. (2000). Host specificity in avian blood parasites: a study of Plasmodium and Haemoproteus mitochondrial DNA amplified from birds. Proceedings of the Royal Society of London B, Vol. 267, pp. 1583- 1589

Bensch, S.; Pérez-Tris, J.; Waldensrtöm, J. \& Hellgren, O. (2004). Linkage between nuclear and mitochondrial DNA sequences in avian malaria parasites: Multiple cases of cryptic speciation? Evolution, Vol. 58, pp. 1617-1621

Bensch, S.; Hellgren, O. \& Pérez-Tris, J. (2009). MalAvi: A public database of malaria parasites and related haemosporidians in avian hosts based on mitochondrial cytochrome b lineages. Molecular Ecology Resources, Vol. 9, pp. 1353-1358

Blackburn, T.M.; Lockwood, J.L. \& Cassey, P. (2009). Avian Invasions. The ecology and evolution of exotic birds. Oxford University Press, ISBN 978- 0199232550, Oxford, UK

Blossey, B. \& Nötzold, R. (1995). Evolution of increased competitive ability in invasive nonindigenous plants: a hypothesis. Journal of Ecology, Vol. 83, pp. 887-889

Callaway, R. M. \& Ridenour, W. M. (2004). Novel weapons: a biochemically based hypothesis for invasive success and the evolution of increased competitive ability. Frontiers in Ecology and the Environment, Vol. 2, pp. 436-433

Charleston, M.A. \& Perkins, S.L. (2002). Lizards, malaria, and jungles in the Caribbean. In: Tangled Trees: Phylogeny, Cospeciation, and Coevolution, R.D.M. Page (Ed.),. Chicago University Press, pp. 65-92, ISBN 978-0226644677, Chicago, USA

Chen, M.; Shi, L. \& Sullivan, D. Jr. (2001). Haemoproteus and Schitosoma synthesize heme polymers similar to Plasmodium hemozoin and $\beta$ - hematin. Molecular and Biochemical Parasitology, Vol. 113, pp. 1-8

Colautti, R. I.; Ricciardi, A.; Grigorovich, I. A. \& MacIsaac, H. J. (2004). Is invasion success explained by the enemy release hypothesis? Ecology Letters, Vol. 7, pp. 733

Danilewsky, V. (1889). Le parasitologie comparie du sang. I. Nouvelles recherches sur les parasites du sang des oiseaux. A. Dame, Kharkoff.

Davidar, P. \& Morton, E. S. (2006). Are multiple infections more severe for purple martins (Progne subis) than single infections? Auk, Vol. 123, pp. 141-147

Dawson, R. D. \& Bortolotti, G. R. (2000). Effects of hematozoan parasites on condition and return rates of American kestrels. Auk, Vol. 117, pp. 373-380.

Diamond, J. (1997). Guns, germs, and steel: the fates of human societies. Random House, ISBN 978-0393317558, New York, USA

Doré, A. B. (1918). Rat trypanosomes in New Zealand. New Zealand Journal of Science and Technology Vol. 1, pp.200 
Dufva, R. (1996). Blood parasitism, health, reproductive success, and egg volume in female great tits Parus major. Journal of Avian Biology, Vol. 27, pp. 83-87

Dufva, R. \& Allander, K. (1995). Intraespecific variation in plumage coloration reflects inmune response in great tit (Parus major) males. Functional Ecology, Vol. 9, pp. 785789

Evans, M. \& Otter, A. (1998). Fatal combined infection with Haemoproteus noctuae and Leucocytozoon ziemanni in juvenile snowy owls (Nyctea scandiaca). Veterinary Records, Vol. 143, pp. 72-76

Fairley, N. H. (1947). Sidelights of malaria in men obtained by subinoculation experiments. Transactions of the Royal Society of Tropical Medicine and Hygiene, Vol. 40, pp. 621-676

Fallis, A. M. \& Desser, S. S. (1977). On species of Leucocytozoon, Haemoproteus, and Hepatocystis. In Parasitic protozoa, J.P. Kreier (Ed.), pp. 239-266, Academic Press, ISBN 004591021 9, New York, USA

Fallon, S.M.; Ricklefs, R.E.; Latta, S.C. \& Bermingham, E. (2004). Temporal stability of insular avian malarial parasite communities. Proceedings of the Royal Society of London B, Vol. 271, pp. 493-500

Fallon, S.; Fleischer, R. \& Graves, G. (2006). Malarial parasites as geographical markers in migratory birds? Biology Letters, Vol. 2, pp.213-216

Fenwick, P. (1980). The effect of Plasmodium berghei, Trypanosoma lewisi, Coryrebacterium parvum, and Mycobacterium bovis (BCG) on the growth and survival of Hymenolepis diminuta in the rat. Parasitology, Vol. 81, pp. 175-183

Freed, L.A.; Cann, R.L.; Goff, M.L.; Kuntz, W.A. \& Bodner, G.R. (2005). Increase in avian malaria at upper elevation in Hawai'I. The Condor, Vol. 107, pp. 753

Garvin, M. C.; Homer, B. L. \& Greiner, E. C. (2003). Pathogenicity of Haemoproteus danilewskyi, Kruse, 1890, in blue jays (Cyanocitta cristata). Journal of Wildlife Diseases, Vol. 39, pp.161-169

Garamszegi, L. Z. (2011). Climate change increases the risk of malaria in birds. Global Change Biology, Vol. 17, pp. 1751-1759

Graham, A.L.; Lamb, T.J.; Read, A.F.\& Allen, J.E. (2005). Malaria filaria co-infection in mice makes malarial disease more severe unless filarial infection achieves patency. Journal of Infectious Diseases, Vol. 191, pp. 410-421

Hellgren, O. (2005). The occurrence of haemosporidian parasites in the Fennoscandian bluethroat (Luscinia svecica) population. Journal of Ornithology, Vol. 146, pp. 55-60

Hobson, K.A.; McFarland, K.P.; Wassenaar, L.I.; Rimmer, C.C. \& Goetz, J.E. (2001) Linking breeding and wintering grounds of Bicknell's thrushes using stable isotope analyses of feathers. Auk, Vol. 118, pp. 16-23

Hobson, K.A.; Bowen, G.; Wassenaar, L., Ferrand, Y. \& Lormee, H. (2004). Using stable hydrogen and oxygen isotope measurements of feathers to infer geographical origins of migrating European birds. Oecologia, Vol. 141, pp. 477-488.

Hobson, K.A. (2005). Stable isotopes and the determination of avian migratory connectivity and seasonal interactions. Auk, Vol. 122, pp.1037-1048

Huijben, S.; Schaftenaar, W.; Wijsman, A.; Paaijmans, K. \& Takken, W. (2007). Avian malaria in Europe: an emerging infectious disease? In: Emerging pests and vector-borne diseases in Europe, W. Takken \& B.G.J. Knols (eds), 59 - 74, Wageningen Academic Publishers, ISBN 978-90-8686-053-1, Wageningen, The Netherlands 
Ishtiaq, F.; Beadell, J.S.; Baker, A.J.; Rahmani, A.R.; Jhala, Y.V. \& Fleischer, R. C. (2006). Prevalence and evolutionary relationships of haematozoan parasites in native versus introduced populations of common myna Acridotheres tristis. Proceedings of the Royal Society of London B, Vol. 273, pp. 587-594

Jarvi, S.I., Atkinson, C.T. \& Fleischer, R.C. (2001). Immunogenetics and resistance to avian malaria in Hawaiian honeycreepers (Drepanidinae). Studies in Avian Biology, Vol. 22, pp. 254-263

Jovani, R. (2002). Malaria transmission, sex ratio and erythrocytes with two gametocytes. Trends in Parasitology, Vol. 18, pp. 537-539

Juhl, J. \& Permin, A. (2002). The effect of Plasmodium gallinaceum on a challenge infection with Ascaridia galli in chickens. Veterinary Parasitology, Vol. 105, pp. 11-19

Keymer, A. E. \& Read, A. F. (1991). Behavioural ecology: the impact of parasitism. In: Parasite-host associations: coexistance or conflict, C. A. Toft, A. Aeschlimann \& L. Boils (Eds.), 37-61, Oxford University Press, ISBN 978-0198548348, Oxford, UK

Knowles, S. C. L., Palinauskas, V. \& Sheldon, B. (2010). Chronic malaria infections increase family inequalities and reduce parental fitness: experimental evidence from a wild bird population. Journal of Evolutionary Biology, Vol. 23, pp. 557-569

Korpimäki, E., Hakkarainen, H. \& Bennett, G. F. (1993). Blood parasites and reproductive success of Tengmalm's owl: detrimental effects on females but not on males? Functional Ecology, Vol. 7, pp. 420-423

Korpimäki, E., Tolonen, P. \& Bennett, G. F. (1995). Blood parasites, sexual selection and reproductive seccess of European kestrels. Ecoscience, Vol. 2, pp. 335-343

Krettli, A.U.; Andrade-Neto, V.F.; Brandao, M.G.L. \& Ferrari, W.M.S. (2001). The search for new antimalarial drugs from plants used to treat fever and malaria or plants ramdomly selected: a review. Memórias do Instituto Oswaldo Cruz, Vol. 96, pp. 10331042

Krettli, A.U. (2009). Antimalarial drug discovery: screening of Brazilian medicinal plants and purified compounds. Expert Opinion on Drug Discovery, Vol. 4, pp. 1-14

Krettli, A.U.; Adebayo, J.O. \& Krettli, L.G. (2009). Testing of Natural Products and Synthetic Molecules Aiming at New Antimalarials. Current Drug Targets, Vol. 10, pp. 261-270

Laird, M. (1995). Background and findings of the 1993-94 New Zealand mosquito survey. New Zealand Entomologist, Vol. 18, pp. 77-90

Levine, N.D. (1988). The Protozoan Phylum Apicomplexa. CRC Press, ISBN 978-0849346538, Boca Ratón, Florida, USA

Lima, M.R.; Simpson, L.; Fecchio, A. \& Kyaw, C. (2010). Low prevalence of haemosporidian parasites in the introduced house sparrow (Passer domesticus) in Brazil. Acta Parasitologica, Vol. 55, pp. 297-303

Mac, M.J.; Opler, P.A.; Puckett Haecker, C.E. \& Doran, P.D. (1998). Hawaii and Pacific islands. Status and Trends of the Nation's Biological Resources. U.S. Department of the Interior, U.S. Geological Survey, ISBN 978-0160532856, Reston, VA, USA

Mack, R.N.; Simberloff, D.; Lonsdale, W.M.; Evans, H., Clout, M. \& Bazzaz, F.A. (2000). Biotic invasions: causes, epidemiology, global consequences and control. Ecological Applications, Vol. 10, pp. 10-689

MacLeod, C.J.; Duncan, R.P.; Parish, D.M.B.; Wratten, S.D. \& Hubbard, S.F. (2005). Can increased niche opportunities and release from enemies explain the success of introduced yellowhammer populations in New Zealand? Ibis, Vol. 147, pp. 598- 607 
Martínez-De-La-Puente, J.; Merino, S.; Tomás, G.; Moreno, J.; Morales, J.; Lobato, E.; GarcíaFraile, S. \& Belda, E. J. (2010). The blood parasite Haemoproteus reduces survival in a wild bird: A medication experiment. Biology Letters, Vol. 6, pp. 663-665

Martinsen, E.S.; Perkins, S.L. \& Schall, J.J. (2008). A three-genome phylogeny of malaria parasites (Plasmodium and closely related genera): Evolution of life-history traits and host switches. Molecular Phylogenetics and Evolution, Vol. 47, pp. 261-273

Marzal, A.; de Lope, F.; Navarro, C. \& Møller, A. P. (2005). Malarial parasites decrease reproductive success: an experimental study in a passerine bird. Oecologia, Vol. 142, pp. 541-545

Marzal, A.; Bensch, S.; Reviriego, M.; Balbontín, J. \& De Lope, F. (2008). Effects of malaria double infection in birds: one plus one is not two. Journal of Evolutionary Biology, Vol. 21, pp. 979-987

Marzal, A.; Ricklefs, R.E.; Valkiūnas, G.; Albayrak, T.; Arriero, E.; Bonneaud, C.; Czirják, G.A.; Ewen, J.; Hellgren, O.; Hořáková, D.; Iezhova, T.A.; Jensen, H.; Križanauskienė, A.; Lima, M.R.; de Lope, F.; Magnussen, E.; Martin, L.B.; Møller, A.P.; Palinauskas, V.; Pap, P.L.; Pérez-Tris, J.; Sehgal, R.N.; Soler, M.; Szöllősi, E.; Westerdahl, H.; Zetindjiev, P. \& Bensch, S. (2011). Diversity, Loss, and Gain of Malaria Parasites in a Globally Invasive Bird. PLoS ONE Vol. 6, e21905, doi:10.1371/journal.pone.0021905

Merino, S.; Moreno, J.; Sanz, J. J. \& Arriero, E. (2000). Are avian blood parasites pathogenic in the wild? A medication experiment in blue tits (Parus caeruleus). Proceedings of the Royal Society of London. B, Vol. 267, pp. 2507-2510

Mooney, H.A. \& Cleland, E.E. (2001). The evolutionary impact of invasive species. Proceedings of the National Academy of Sciences of the United States of America, Vol. 98, pp. 5446-5451

Mu, J.; Joy, D.A.; Duan, J.; Huang, Y.; Carlton, J.; Walker, J.; Barnwell, J.; Beerli, P.; Charleston, M.A.; Pybus, O.G. \& Su, X.Z. (2005). Host switch leads to emergence of Plasmodium vivax malaria in humans. Molecular Biology and Evolution, Vol. 22, pp. 1686-1693

McGhee, R. B.; Singh, S. D. \& Weathersby, A. B. (1977). Plasmodium gallinaceum: vaccination in chickens. Experimental Parasitology, Vol. 43, pp. 231- 238

Pagenkopp, K.M.; Klicka, J.; Durrant, K.L.; Garvin, J.C. \& Fleischer, R.C. (2008) Geographic variation in malarial parasite lineages in the common yellowthroat (Geothlypis trichas). Conservation Genetics, Vol. 9, pp. 1577-1588

Palinauskas, V.; Markovets, M.Yu; Kosarev, V.V.; Efremov, V.D.; Sokolov, L.V. \& Valkiunas, G. (2005). Occurrence of avian haematozoa an Ekaterinburg and Ircutsk districts of Russia. Ekologija Vol. 4, pp. 8-12

Palinauskas, V.; Valkiūnas, G.; Bolshakov, V. C. \& Bensch, S. (2008). Effects of Plasmodium relictum (lineage P-SGS1) on experimentally infected passerine birds. Experimental Parasitology, Vol. 120, pp. 372-380

Palinauskas, V.; Valkiūnas, G.; Križanauskienè, A.; Bensch, S. \& Bolshakov, C. V. (2009). Plasmodium relictum (lineage P-SGS1): Further observation of effects on experimentally infected passeriform birds, with remarks on treatment with Malarone $^{\mathrm{TM}}$. Experimental Parasitology, Vol. 123, pp. 134-139 
Palinauskas V.; Valkiūnas G.; Bensch S. \& Bolshakov V. C. (2011). Plasmodium relictum (lineage SGS1) and Plasmodium ashfordi (lineage GRW2): The effects of the coinfection on experimentally infected passerine birds. Experimental Parasitology, Vol. 127, pp. 527-533

Paul, R.E.; Nu, V.A.; Krettli, A.U. \& Brey, P.T. (2002). Interspecific competition during transmission of two sympatric malaria parasite species to the mosquito vector. Proceedings of the Royal Society of London. B, Vol. 269, pp. 2551- 2557

Pérez-Tris, J. \& Bensch, S. (2005). Diagnosing genetically diverse avian malaria infections using mixed-sequence analysis and TA-cloning. Parasitology, Vol. 131, pp. 1-9

Perez-Tris, J.; Hasselquist, D.; Hellgren, O.; Krizanauskiene, A.; Waldenstrom, J. \& Bensch, S. (2005). What are malaria parasites? Trends in Parasitology, Vol.. 21, pp. 209-211

Perez-Tris, J.; Hellgren, O.; Krizanauskiene, A.; Waldenstrom, J.; Secondi, J.; Bonneaud, C.; Fjeldsa, J.; Hasselquist, D. \& Bensch, S. (2007). Within-host speciation of malaria parasites. PLoS ONE, Vol. 2, pp. 1-7

Prenter, J.; MacNeil, C.; Dick, J. T. A. \& Dunn, A. M. (2004). Roles of parasites in animal invasions. Trends in Ecology and Evolution, Vol. 19, pp. 385-390

Råberg, L; Graham, A. \& Read, A.F. (2009). Decomposing health: tolerance and resistance to parasites in animals. Proceedings of the Royal Society of London. B, Vol. 364, pp. 37-49.

Rätti, O.; Dufva, R. \& Alatalo, R. V. (1993). Blood parasites and male fitness in the pied flycatcher. Oecologia, Vol. 96, pp. 410-414

Rintamäki, P.T.; Ojanen, O., Pakkala, H. \& Tynjälä, M. (1998). Blood parasites of migrating Willow Warblers (Phylloscopus trochilus) at a stopover site. Canadian Journal of Zoology, Vol. 76, pp.984-988

Roehl, W. (1926). Die Wirkung des Plasmochins auf die Vogelmalaria. Naturwissenschaften, Vol. 14, pp. 1156-1159

Sá, M. R. (2011). Studies of avian malaria and Brazil in the international scientific context (1907-1945). História, Ciências, Saúde-Manguinhos, Vol. 18, pp. 499-518

Sanz, J.J.; Arriero, E.; Moreno, J. \& Merino, S. (2001). Interactions between hemoparasite status and female age in the primary reproductive output of Pied Flycatchers. Oecologia, Vol. 126, pp.339-344

Schall, J.J. (2002). Parasite virulence. In: The Behavioural Ecology of Parasites, E.E. Lewis, J.F. Cambell \& M.V.K. Sukhdeo (Eds.), 283-313, CABI Publishing, ISBN 9780851996158, Oxon, UK

Sergent, E. \& Sergent E. (1921). Étude expérimentale du Paludisme des oiseaux à Plasmodium relictum, transmis par Culex pipiens. Archives des Instituts Pasteur de l'Afrique du Nord, Vol 1, pp. 1-32

Shwartz, A.; Strubbe, D.; Butler, C.J.; Matthysen, E. \& Kark, S. (2009). The effect of enemyrelease and climate conditions on invasive birds: a regional test using the Roseringed Parakeet (Psittacula krameri) as a case study. Diversity and Distributions, Vol. 15, pp. 310-318

Shurulinkov, P. \& Ilieva, M. (2009). Spatial and temporal differences in the blood parasite fauna of passerine birds during the spring migration in Bulgaria. Parasitology Research, Vol. 104, pp. 1453-1458

Sillett, T. S. \& Holmes, R.T. (2002). Variation in survivorship of a migratory songbird throughout its annual cycle. Journal of Animal Ecology, Vol. 71, pp. 296-308 
Slater, L.B. (2009). War and disease: biomedical research on malaria in the twentieth century. Rutgers University Press, ISBN 978-0813544380, New Brunswick, NJ, USA

Spencer, K.A.; Buchanan, K.L.; Leitner, S.; Goldsmith, A.R. \& Catchpole, C.K. (2005). Parasites affect song complexity and neural development in a songbird. Proceedings of the Royal Society of London. B, Vol. 272, pp. 2037-2043

Svennson, E.I. \& Råberg, L. (2010). Resistance and tolerance in animal enemy-victim coevolution. Trends in Ecology \& Evolution, Vol. 25, pp. 267-274

Sweeney, A. W. (2000). Wartime research on malaria chemotherapy. Parassitologia, Vol. 42, pp. 33-45

Tang, J.; Inoue, M.; Sunahara, T.; Kanda, M.; Kaneko, O. \& Culleton, R. (2010) Intra-host dynamics of mixed species malaria parasite infections in mice and mosquitoes. Malaria Journal, Vol. 9, pp. O31

Taylor, L. H.;MacKinnon, M. J. \& Read, A. (1998). Virulence of mixed-clone and single-clone infections of the rodent malaria Plasmodium chabaudi. Evolution, Vol. 52, pp. 583-591

TEEB. (2008). The Economics of Ecosystems and Biodiversity: An Interim Report', European Commission, Brussels. URL:

www.teebweb.org/LinkClick.aspx?fileticket=u2fMSQoWJf0\%3d\&tabid=1278\&lan guage $=$ en-US.

Tomás, G.; Merino, S.; Martínez, J.; Moreno, J. \& Sanz, J. J. (2005). Stress protein levels and blood parasite infection in blue tits (Parus caeruleus): a medication field experiment. Annales Zoologici Fennici, Vol. 42, pp. 45-56

Tompkins, D.M. \& Poulin, R. (2006). Parasites and biological invasions. In: Biological Invasions in New Zealand, R.B. Allen \& W.G. Lee (Eds.),67-84, Springer-Verlag, ISBN 978-3-540-30022-9, Berlin Heidelberg, Germany

Torchin, M. E.; Lafferty, K. D.; Dobson, A. P.; McKenzie, V. J. \& Kuris, A. M. (2003). Introduced species and their missing parasites. Nature, Vol. 421, pp. 628-630

Trager, W. (1950). Studies on the extracellular cultivation of an intracellular parasite (avian malaria). The Journal of Experimental Medicine, Vol. 92, pp. 349- 365

Valkiūnas, G. (2005). Avian malaria parasites and other haemosporidia. CRC Press, ISBN 9780415300971, Boca Raton, Florida, USA

Valkiunas, G.; Anwar, A.M.; Atkinson, C.T.; Greiner, E.C.; Paperna, I. \& Peirce, M.A. (2005). What distinguishes malaria parasites from other pigmented haemosporidians? Trends in Parasitology, Vol. 21, pp. 357-358

Valkiūnas, G.; Žičkus, T.; Shapoval, A. P. \& Iezhova, T. A. (2006a). Effect of Haemoproteus belopolskyi (Haemosporida: Haemoproteidae) on body mass of the Blackcap Sylvia atricapilla. Journal of Parasitology, Vol. 92, pp. 1123-1125

Valkiūnas, G.; Bensch, S.; Iezhova, T. A.; Križanauskienè, A.; Hellgren, O. \& Bolshakov, C. (2006b). Nested cytochrome b polymerase chain reaction diagnostics underestimate mixed infections of avian blood haemosporidian parasites: microscopy is still essential. Journal of Parasitology, Vol. 92, pp. 418-422

Van Riper III, C.; Van Riper, S. G.; Goff, M. L. \& Laird, M. (1986). The epizootiology and ecological significance of malaria in Hawaiian land birds. Ecological Monographs, Vol. 56, pp. $327-344$

von Rönn, J. (2010). Migration and blood parasites in barn swallows. PhD thesis, Max-PlanckInstitute for Evolutionary Biology, Plön, Germany. 
Wakelin, D. (1996). Immunity to parasites: How parasitic infections are controlled. Cambridge University Press, ISBN 978-0521436359, Cambridge, UK

Waldenström, J.; Bensch, S.; Kiboi, S.; Hasselquist, D. \& Ottosson, U. (2002). Cross-species infection of blood parasites between resident and migratory songbirds in Africa. Molecular Ecology, Vol. 11, pp. 1545-1554

Wasielewski, T. K. W. N. (1904). Studien und Mikrophotogramme zur Kenntnis der Pathogenen Protozoen. Nabu Press, ISBN 978-1143527210, Leipzig, Germany.

Wassenaar, L.I. \& Hobson, K.A. (2000). Stable-carbon and hydrogen isotope ratios reveal breeding origins of red-winged blackbirds. Ecological Applications, Vol. 10, pp. 911916

Weatherhead, P. J. \& Bennett, G. F. (1992). Ecology of parasitism of brown-headed cowbirds by haematozoa. Canadian Journal of Zoology, Vol. 70, pp. 1-7

Webster, M. S.; Marra, P. P.; Haig, S. M.; Bensch, S. \& Holmes, R. T. (2002). Links between worlds: unravelling migratory connectivity. Trends in Ecology and Evolution, Vol. 17, pp. 76-83

Wilson, M.L. (2001). Ecology and infectious disease. In: Ecosystem change and public health, J. Aron, J.A. Patz (eds), 283-324, The Johns Hopkins University Press, ISBN 9780801865824, Baltimore, USA

Yohannes, E.; Križanauskienė, A.; Valcu, M.; Bensch, S. \& Kempenaers, B. (2008). Prevalence of malaria and related haemosporidian parasites in two shorebird species with different winter habitat distribution. Journal of Ornithology, Vol. 150, pp. 287-291

Zehtindjiev, P.; Ilieva, M.; Westerdahl, H.; Hansson, B.; Valkiūnas, G. \& Bensch, S. (2008). Dynamics of parasitemia of malaria parasites in a naturally and experimentally infected migratory songbird, the great read warbler Acrocephalus arundinaceus. Experimental Parasitology, Vol. 119, pp. 99-110 


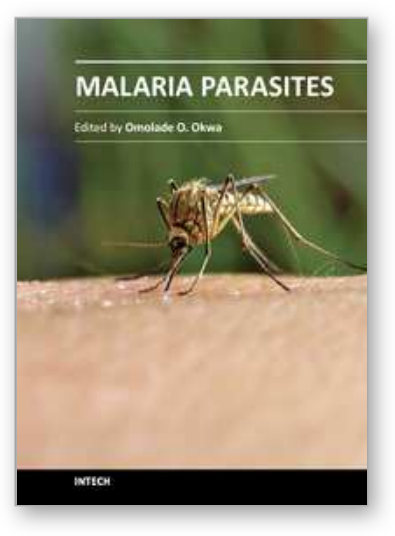

\author{
Malaria Parasites \\ Edited by Dr. Omolade Okwa
}

ISBN 978-953-51-0326-4

Hard cover, 350 pages

Publisher InTech

Published online 30, March, 2012

Published in print edition March, 2012

Malaria is a global disease in the world today but most common in the poorest countries of the world, with $90 \%$ of deaths occurring in sub-Saharan Africa. This book provides information on global efforts made by scientist which cuts across the continents of the world. Concerted efforts such as symbiont based malaria control; new applications in avian malaria studies; development of humanized mice to study P.falciparium (the most virulent species of malaria parasite); and current issues in laboratory diagnosis will support the prompt treatment of malaria. Research is ultimately gaining more grounds in the quest to provide vaccine for the prevention of malaria. The book features research aimed to bring a lasting solution to the malaria problem and what we should be doing now to face malaria, which is definitely useful for health policies in the twenty first century.

\title{
How to reference
}

In order to correctly reference this scholarly work, feel free to copy and paste the following:

Alfonso Marzal (2012). Recent Advances in Studies on Avian Malaria Parasites, Malaria Parasites, Dr. Omolade Okwa (Ed.), ISBN: 978-953-51-0326-4, InTech, Available from:

http://www.intechopen.com/books/malaria-parasites/recent-advances-in-studies-on-avian-malaria-parasites

\section{INTECH}

open science | open minds

\section{InTech Europe}

University Campus STeP Ri Slavka Krautzeka 83/A 51000 Rijeka, Croatia Phone: +385 (51) 770447

Fax: +385 (51) 686166 www.intechopen.com

\section{InTech China}

Unit 405, Office Block, Hotel Equatorial Shanghai No.65, Yan An Road (West), Shanghai, 200040, China 中国上海市延安西路65号上海国际贵都大饭店办公楼405单元 Phone: +86-21-62489820

Fax: +86-21-62489821 
(C) 2012 The Author(s). Licensee IntechOpen. This is an open access article distributed under the terms of the Creative Commons Attribution 3.0 License, which permits unrestricted use, distribution, and reproduction in any medium, provided the original work is properly cited. 